\title{
LIVROS E CULTURA
}

\author{
LIBROS Y CULTURA
}

ECO, U.; CARRIÈRE, J-C. Não contem com o fim do livro. Tradução do francês por A. Telles. Rio de Janeiro: Ed. Record, 2010. 269 p.

A relação entre o livro, a cultura e o desenvolvimento do homem e da sociedade é inegável. O Brasil levou muito tempo para poder produzir seus livros que antes eram impressos na Europa, mas evoluiu e hoje já está produzindo ebooks. No contexto desta transformação é que se situa o presente livro. Trata-se de matéria da qual intelectuais, pesquisadores e educadores precisam manter-se informados para poderem refletir e ter opções que ultrapassem as contingências econômicas.

A obra é resultado de encontros de dois expontes: Umberto Eco, conhecido semiólogo, professor e premiado escritor e Jean-Claude Carrière, conhecido roteirista e escritor francês. O prefácio é assinado por Tonnat, que é ensaísta, jornalista e escritor que foi o mediador do diálogo entre os dois autores. Começa lembrando a constante falácia de se considerar que um avanço ou inovação substituirá algo já instituído. A preocupação está em saber que mudanças a leitura na tela introduzirá no leitor. Esclarece que inicialmente as conversas entre os autores não era analisar as transformações e perturbações pelo uso em grande escala do livro no formato eletrônico. Mas o tema surgiu, avolumou-se e resultou na obra aqui resenhada. Conclui acertadamente dizendo que as conversas irão arrebatar todos os leitores e apaixonados pelo objeto livro. Não é impossível que também alimentem a nostalgia dos detentores de e-books (p. 14) em relação ao texto impresso. 
As conversas de Eco (UE) e Carrière (JCC) estão organizadas em 15 tópicos, o primeiro dos quais tem por título O livro não morrerá. Ambos concordam que a previsão de que o livro vai desaparecer é uma falácia. Discutem as vantagens dos e-books na recuperação de clássicos, obras de acesso difícil, esgotadas, conforto de transporte, de ler em qualquer lugar. É possível que outras tecnologias venham substituir os e-books, mas o livro manterá sua presença. JCC lembra (p. 19): O cinema e o rádio, a própria televisão, não tiraram nada do livro, nada que Ihe tenha causado "danos".

$\mathrm{Na}$ conversa seguinte discutem o Nada mais efêmero do que os suportes duráveis. JCC lembra sua experiência em uma escola de cinema, cuja tecnologia e estratégias em 20 anos foi superada. UE lembra as facilidades de acesso a obras online a preços baixos. Relembram a rápida superação dos CD-ROM e DVD e a eterna reorganização que requerem e o culto decorrente de se poder trabalhar com originais textuais de roteiros de filmes clássicos, dos textos em papiros. Tecem um discurso partilhado rico de exemplos dos esforços de preservação, das diferenças entre gerações em relação ao livro. São exemplos que mostram, entre outros fatos, a ilusão de que com o e-book se alcançou maior agilidade e velocidade. Subjacente está a problemática educacional.

O capítulo 3 trata da confiabilidade da informação em decorrência do nível em que ela é produzida e difundida, como isto é visto e operacionalizado pelas gerações mais velhas e pelas novas. Manifestam suas preocupações com os resumos de clássicos, mesmo considerando que há resumos e resumos (p. 51), todos simulam a obra inteira. Fecham lembrando a velocidade com que ocorre a obsolescência de conhecimento na atualidade.

O capítulo seguinte continua discutindo a difícil conservação do que precisa ser conservado, ficando evidente que memória não é apenas armazenamento. As relações com o aprender a aprender é essencial em todas as áreas de conhecimento.

A matéria tem continuidade em $A$ revanche dos filtrados (capítulo 5), em que discutem a questão da memória incontrolável com a Internet. JCC lembra que o meio oferece uma informação bruta, sem nenhum discernimento, ou quase isso, sem controle das fontes e nem hierarquização ( $p$. 71), o que é um perigo que 
exemplifica com dados da história. UE lembra que se está rompendo o filtro material feito pelas culturas. JCC lembra que na selva da informação, cada qual precisa desbravar o próprio caminho. Vários exemplos históricos de similaridades diversas são oferecidos.

O capítulo 6 tem por título: Todo livro publicado hoje é um pós-incunábulo, no qual os autores tratam de variáveis que levam ao gostar de livros e a ser bibliófilos, que é uma característica dos dois. Entre elas aparece o acaso, a possibilidade de reconstrução do passado de forma dinâmica, pelos vestígios deixados pelos leitores antecedentes, notas às margens, há também a curiosidade pelos que tiveram o livro antes do atual dono, relembram a falta de alguns pensadores e religiosos não terem escrito livros. Lamentam a perda gradual da correspondência escrita à mão bem como a perda de profissões relacionadas à escrita e ao livro. Também discutem a importância do rascunho na produção textual. UE diz: Nós utilizamos o computador, mas imprimimos como loucos. Para um texto de dez páginas, imprimo cinqüenta. Estou matando uma dúzia de árvores, ao passo que talvez não matasse mais de dez antes da entrada do computador na minha vida (p. 101). Consideram as relações autorcomputador-texto. O valor das obras manuscritas é considerado em seus vários aspectos, incluindo a relação do autor com o próprio texto.

No capítulo seguinte discutem a magia que envolve as situações com que alguns livros chegam à mão de bibliófilos, lembrando casos pessoais e de outras pessoas, o trabalho de detetive, a influência do acaso. Expressam seus desejos nesta área. Comentam sobre os dilapidadores e como se perde a história.

O tema tem prosseguimento no oitavo capítulo, em que o assunto do diálogo é a confiabilidade dos livros antigos como testemunho do passado. UE diz que, para ele, embora os livros possam ser testemunhas discutíveis, ensinam alguma coisa sobre o passado. JCC tem posição similar. Lembram que muitos dos textos que foram preservados possivelmente não eram os melhores da época, por exemplo, preservou-se às vezes textos vulgares, citam diversos exemplos. A problemática do que salvar e transmitir, bem como, quem e como a seleção é feita, foi foco de uma conversa elucidativa de que o que veio do passado muitas vezes foi obra de cretinos, imbecis ou adversários (p. 145). 
Em Nada detém a vaidade (capítulo 9) dão continuidade às considerações sobre o que legaram as obras do passado. Exemplos ontológicos são lembrados pelos interlocutores em que loucura ou pura vaidade estão subjacentes ao fato do texto ter sido escrito e divulgado. Podem ser citadas as considerações sobre $A$ Loucura de Jesus, as perseguições políticas, religiosas, nacionalismos exacerbados e ilógicos, até chegarem às editoras que publicam qualquer obra desde que por conta do autor etc.

O tema se expande no capítulo dez que trata do Elogio da Burrice, que é o tema da introdução do Dicionário da Burrice, em que tudo de idiota escrito sobre os negros, os judeus, os chineses, as mulheres, os grandes artistas foi colhido e considerado por JCC e Bechtel seu coautor como infinitamente mais revelador do que as análises inteligentes (p. 171). O diálogo ágil e rico é muito enriquecedor além do que os exemplos são muito sugestivos.

A preocupação com a censura e com a Internet está subjacente na prosa seguinte, em que ficam patentes os riscos dos escritores (inclusive de vida) quando algum poder ditatorial de religião ou estado exercem a força e o poder para calar com arbitrariedade os seus críticos ou os que representam pensamentos distintos. Consideram que ainda se está longe de se vencer esta situação. UE lembra a dificuldade de se vencer a censura por adição quando há excesso de informação e manipulação da verdade. Os bons jornais conseguem, ainda que indiretamente, superar esta forma de censura. Também discutem como a Internet está tornando a censura difícil, dando voz a situações em que a censura impõe silêncio. É uma esperança ainda que frágil.

O assunto tem continuidade no capítulo $A$ censura pelo fogo, em que retomam a queima de livros que UE lembra estar presente desde a origem dos livros. Relembram eventos históricos, textos literários e os esforços de alguns verdadeiros heróis para salvar os livros e a cultura neles guardada. Analisaram o que leva alguns a gestos desta natureza e seus desvios.

No $13^{\circ}$ texto, o leitor se depara com uma conversa sobre o que não leram. UE retoma Bayard para lembrar que há mais livros neste mundo do que horas de que dispomos para tomar conhecimento deles (p. 217) e tece considerações sobre obras que exercem grande influência sobre as pessoas mesmo que elas 
não as tenham lido. Cita exemplos pessoais. JCC caminha na mesma direção mostrando que muitos são deixados para depois, mas pode ser muito tarde, talvez até numa outra vida (p. 219). Também cuidam da memória da matéria lida ou assistida. Retomam a um tipo específico de censura: a indicação de obras a serem lidas e nunca serem objeto de leitura. Além dos censores já referidos, lembram intelectuais que fazem isto, críticos de arte, adeptos de dadas teorias ou posições, que se arvoram em defender uns e a destruir outros. Como JCC lembra, isto é muito comum entre surrealistas. Em seguida, vem para a conversa os autores que nunca existiram e retoma o clássico escritor inventado na Feira do Livro de Frankfurt, a que chamaram de Milo Temesvar, que teria escrito Let me say now, de grande êxito. Divulgado na feira, o falso autor e livro, logo se espalhou a informação iludindo a muitos.

O tema seguinte é a Religião do Livro, pois muitas se referem a livros, sendo o mais antigo a Bíblia Hebraica. Vários problemas estão implícitos. JCC explicita parte de sua trajetória como leitor, sendo que seu primeiro contato com o sagrado foi na missa, em que o padre lia o evangelho, a vivência de credibilidade em alguma informação só por estar em um livro a crença que o levou a se tornar cedo um bibliófilo. UE teve uma história diferente contando com a influência do avô paterno que era tipógrafo e encadernador de livro. A herança o pôs em contato com vários tipos de livros. Ambos lembram a influência da leitura infantil, da forma como as várias culturas os trataram e tratam.

O último diálogo é resultado de uma preocupação constante entre todos que acumulam livros, especialmente os que organizam uma biblioteca, depois que morrem. JCC relata sua vivência de ter sido obrigado a vender parte de sua biblioteca, o destino da atual será decidido por sua mulher e filha que são as herdeiras. UE não quer que sua biblioteca seja dispersada. A família pode doá-la ou vendê-la, mas completa. Discutem várias preocupações, entre elas, com os ladrões de livro.

É uma leitura muito reforçadora para quem gosta de ler e de livros, muito educativa, prazerosa. É como estar ouvindo ao vivo dois autores bibliófilos admiráveis, lúcidos, ponderados, sinceros. É uma conversa muito enriquecedora. Além disso, é uma obra de grande utilidade em cursos que enfoquem a leitura em seus múltiplos aspectos. 
Geraldina Porto Witter - gpwitter@uol.com.br Doutora em Ciências. Livre-docente em Psicologia Escolar. Professora Emérita da UFPa e do UNIPE. Coordenadora geral da Pós-Graduação Stricto Senso da UNICASTELO.

Title

Books and Culture

\section{Titulo}

Libros y la Cultura 